\section{Forestry Research}

The Forest Products Research Laboratory at Princes Risborough has begun a new issue entitled Forest Products Research Records, of which Nos. 1 and 2 have been issued (H.M. Stationery Office, 1935). No. 1 deals with the testing of timbers at the Forest Products Research Laboratory, and describes in clear language the raison d'être for the Laboratory and the objects at which it aims. It is pointed out that the object underlying the work of investigating the properties of timbers, the practical application of the results of the tests and their importance to the timber-using professions and industries as well as to timber merchants, are not fully understood. Nor are the facilities offered by the Laboratory for supplying information fully realised. It is the object of the Records to supply this want. The first number describes the work of the different sections of the Laboratory under the headings : structure, timber physics, seasoning, timber mechanics, woodworking and preservation, with sections dealing with entomology, mycology, wood chemistry and utilisation.

IN the second number of the Forest Products Research Records the subject of "The Strength Tests of Structural Timbers" is discussed. Both Canada and the United States have been engaged upon research work in this direction for a number of years. Until recently the subject has received very little attention in Europe, which accounts perhaps for the fact that handbooks providing tables do not agree among themselves owing to important factors being overlooked by earlier investigators. For example, mention is made of one record which cites Memel redwood as 60 per cent and English oak as 20 per cent stiffer than greenheart, whereas it has now been established that redwood and oak are approximately equal in this property and no more than half as stiff as greenheart. With the object of coming into line with the Canadian and American research work, an extensive programme of tests was commenced some time ago at Princes Risborough. Work was started in testing redwood from the White Sea and from Geflé. The Timber Trade Federation became in. terested in the work, and with its co-operation the scope was considerably extended. The results of the tests on redwood from those two areas are detailed in the Record.

\section{New Box Testing Laboratory}

THE Department of Scientific and Industrial Research has set up equipment at the Forest Products Research Laboratory for testing packing-cases, boxes, etc., under stresses similar to those encountered during rail or road transport. The installation is the first of its kind in Great Britain, but several are in use in the United States, where the experience gained has considerably reduced the claims for damages paid by the railways. The plant at Princes Risborough tests both the endurance and strength of the boxes. For the former test, the cases are placed inside a large rotating drum, which revolves twice a minute, wooden baffles on the inner face causing the article to fall in different positions in turn. A moderately well-made container was found to collapse after about thirty falls, whereas one of really good design could withstand 150 or more falls. A 'dropping machine' tests the resistance to falls on the face, corner or edges at will, while in a further apparatus resistance to crushing can be determined. The efficiency of nailing, different types of fastenings and packings are also being investigated, and on behalf of the Ministry of Agriculture special tests are being made with the view of drawing up a standard specification for fibre-board containers for National Mark eggs. The Box Testing Laboratory will be available to manufacturers and others who wish to study possible improvements in methods of box construction and in the packing of contents to give the greatest protection. The scale of charges, and a statement of the conditions under which tests will be made, can be obtained from the Director, Forest Products Research Laboratory, Princes Risborough, Bucks.

\section{Air-Conditioning in the Tropics}

ATmospheric conditions in the tropics have serious effects, both physical and mental, upon the inhabitants. In an article in the Electrical Review of November 8, Prof. C. A. Middleton Smith of the University of Hong-Kong states that it is difficult for those who live in temperate regions to realise the depression produced on human energy by living for months in a climate with a night and day temperature of about $90^{\circ} \mathrm{F}$. and a relative humidity of more than 90 per cent. With the help of electrical power and the new methods of producing cold mechanically, it is now possible to manufacture climatic conditions that are almost perfect. By the use of a small electrically driven machine in his private room in the University, Prof. Smith can make the climate in it as pleasant as on a summer day in England. Six hours after the machine has been at work, it has extracted a gallon and a half of water from the air in the room. The effect of the two contrasting atmospheric conditions within and outside the room upon bodily comfort is most marked, and he has found by experience that he can double his lecture hours and yet be less fatigued at the end of the day. He says that no educated person in the tropics who can afford an electrically driven refrigerator would now risk having a 'disease carrying' ice box. He has for the last sixteen years advocated air-conditioning in the tropics. One of the most extensive applications of the system in China to-day is that of the new million pound building of the Hong-Kong and Shanghai Bank. There are six airconditioning plants for the whole building. Electric motors are used for driving the ammonia compressors. Three pumps are required for the condenser water circulation and there are six inlet fans which drive 229,000 cubic feet of air a minute. The total rating of the electric motors used is 800 horse-power.

\section{Radio Research Laboratories Abroad}

THE rapid and widespread growth of radio communication and its associated industries has been one of the most notable events during the past fifteen 